\title{
Long-term outcome after bilateral lung transplantation - a retrospective study from a low-volume center experience
}

Shun-Mao Yang ${ }^{1 \dagger}$, Shu-Chien Huang ${ }^{1 \dagger}$, Shuenn-Wen Kuo ${ }^{1}$, Pei-Ming Huang ${ }^{1}$, Sung-Ching Pan², Jang-Ming Lee ${ }^{1}$, Hong-Shiee Lai ${ }^{1}$ and Hsao-Hsun Hsu ${ }^{1 *}$

\begin{abstract}
Background: The aim of this study is to review the long-term outcomes of bilateral lung transplantation (BLTX) in our institution and examine the potential issues that may influence outcomes in a low-volume center.

Methods: A retrospective review of BLTx performed in our institution between July 2006 and December 2012 was conducted. Standardized donor selection, procurement, and preservation protocols for brain-dead donors were applied. Measured outcomes were in-hospital mortality and actuarial survival using the Kaplan-Meier method.

Results: Twenty-five consecutive patients (13 male, 12 female) underwent BLTX with a mean age of $41.8 \pm 13.5$ years. Before $L T x$, the mean body mass index was $18.3 \pm 3.1 \mathrm{~kg} / \mathrm{m} 2$. Seven of these patients (28\%) required oxygen supplementation at rest before $L T x$, while the remaining patients (72\%) required noninvasive mechanical ventilation $(n=6,24 \%)$, invasive mechanical ventilation $(n=9,36 \%)$ or extracorporeal membrane oxygenation $(E C M O)(n=3$, 12\%). The lung grafts were procured from brain-dead donors with the mean age of $26.8 \pm 11.4$ year and the best $\mathrm{PaO} 2$ / FiO2 ratio of $513 \pm 77$ before procurement. All cross match results between same-race donors and recipients were negative. The percentage of same-sex matching and CMV mismatching were $64 \%$ and $4 \%$, respectively. The mean time listed on the transplant list was $308 \pm 261$ days. The mean ischemic time for the first and second grafts were $222 \pm 62$ and $361 \pm 67$ minutes. During transplantation, 22 (88\%) patients depended on ECMO and one (4\%) on cardiopulmonary bypass support. All but two patients (82\%) were discharged home in good condition; two (8\%) patients died within 3 months after BLTX. The cumulative survival rates at 1-, 2-, 3-, and 5-years were 88\%, 83\%, $72 \%$, and $72 \%$, respectively.
\end{abstract}

Conclusions: Although the comparatively few annual LTx performed is consistent with the low donation rate, our single-center growing experience demonstrates that good post-lung transplant outcomes can be achieved at a low-volume LTx center.

Keywords: Lung transplantation, ECMO, Low-volume center

\section{Background}

Owing to the development of improved immunosuppressants and refinements in surgical technique, lung transplantation (LTx) has become the standard of care for most causes of end-stage lung disease over the last two decades. The first LTx in Taiwan was performed in

\footnotetext{
* Correspondence: ntuhsu@gmail.com

${ }^{\dagger}$ Equal contributors

'Department of Surgery, National Taiwan University Hospital and National Taiwan University College of Medicine, No. 7, Chung-Shan South Road,

Taipei, Taiwan

Full list of author information is available at the end of the article
}

1991, but by the end of 2013, the total number of LTx was less than 150 cases due to the shortage of suitable cadaveric lung donors. Currently, there are eight medical centers authorized to perform LTx in Taiwan; however, none of them have been able to reach 10 LTx per year. The official transplantation report published in 2011 by the Taiwan Organ Registry and Sharing Center (TORSC) demonstrated that the national LTx survival rates (or the average survival rates of all LTx centers) from January 2006 to December 2010 in Taiwan were 65\% at one year and $56 \%$ at 3 years, respectively. These numbers are 
inferior to the worldwide average data published by International Society for Heart and Lung Transplantation (ISHLT) [1]. This has led some physicians to reexamine the risks and benefits of LTx, leading to delayed referral of potential candidates. In the TORSC report, however, some important issues affecting the LTx outcomes were not well-examined. The national donation rate, the varieties between different transplant centers, the effects of transplant center volume, the urgencybased organ allocation policy, and donor and recipient matching all impact survival after LTx. In an attempt to address the void of information and provide more clarity regarding the current information, we report our single-center experience with long-term outcomes after bilateral LTx (BLTx) and evaluate the effects of several important issue that may influence the long-term outcome of LTx.

\section{Methods}

\section{Study protocol}

We performed a retrospective analysis of consecutive patients who have undergone BLTx at the National Taiwan University hospital from July 2006 to December 2012, excluding heart-lung transplantation. Donor, recipient, and surgical data were extracted from patient charts and the Transplant database. This study was approved by the Institutional Review Board of National Taiwan University Hospital, with the informed consent waived.

\section{Recipient and donor selection}

The criteria for donor and recipient selection were identical to those established by the ISHLT. All donor lungs were retrieved from brain-dead donors. In Taiwan, the preference in donor allocation is given to patients with the highest short-term risk of death. When the waitinglists were listed on the national organ allocation network, they were categorized into three different status according to the disease severity. The status II meant the patient has been qualified as a waiting list and could wait for a suitable donor. The status IB meant the waiting-list needed to be hospitalized due to disease progress. The status IA meant the waiting-list has already relied on ventilator or ECMO support. The first priority of lung donor allocation was the severity of recipient's disease, which meant that the more severe the underlying disease, the more preference for organ allocation. Because the total national number of LTx in Taiwan was less than 150 cases, the post-LTx survival did not take into account for organ allocation. The other priorities of organ allocation included the results of cross-matching between donor and recipient, and size matching. Because Taiwan is a small island and the national transplant network run well, we have enough time to perform the cross-matching tests and wait for the results before performing LTx. Therefore, the cross-matching results between donors and recipients were all negative in our LTx patients.

\section{Lung transplant protocols}

During the study period 2006 to 2012, standardized protocols were applied; these have been described previously but are summarized briefly here [2]. All donors were evaluated by our institution's transplant surgeons. Techniques used to assess lung quality included chest radiography, arterial blood gas, bronchoscopy, and visual inspection. For donor lung procurement, a bolus injection of prostaglandin E1 $500 \mu \mathrm{g}$ was administered into the main pulmonary artery immediately before crossclamping the aorta. The donor lung was perfused with $70 \mathrm{~mL} / \mathrm{kg}$ of Perfadex (Vitrolife AB, Goteborg, Sweden) anterograde through the main pulmonary artery and 1 liter of Perfadex retrograde through the pulmonary veins. BLTx was carried out through a clamshell incision from the $4^{\text {th }}$ or $5^{\text {th }}$ intercostal space. The intraoperative extracorporeal membrane oxygenation (ECMO) system was routinely set up to provide adequate hemodynamic support during BLTx when the recipient already depended on ventilator or ECMO support before BLTx, or when the recipient could not tolerate pneumonectomy of the first native lung. In general, ECMO was weaned off in the operating room after BLTx. However, if there were signs of severe reperfusion lung edema or acute primary graft dysfunction that did not allow the transplanted lung to function well, ECMO was continued during transport from the operating room to the intensive care unit (ICU). Protective ventilator management with low tidal volumes $(6 \mathrm{~mL} / \mathrm{kg}$ of the donor body weight) and high positive end-expiratory pressure was used postoperatively. Early adequate enteral nutrition was achieved via nasal feeding tube inserted to the proximal jejunum under endoscopic guidance 2 days after LTx. A triple drug regimen, including a calcineurin inhibitor (cyclosporine or tacrolimus), an antimetabolite (azathioprine or mycophenolate mofetil), and corticosteroids, was used for maintenance immunosuppression. The choice of antibiotics was based on the results of sputum culture from donor and recipient. In the early post-transplant period, prophylactic valganciclovir was routinely used to prevent cytomegalovirus. Voriconazole was used for fungus and yeast if infection was suspected.

\section{Statistical analysis}

Continuous data are expressed as the mean with the standard deviation; proportions are represented as numbers (\%). Categorical data are presented as a frequency and percentage. Cumulative survival following lung transplantation was determined using the Kaplan-Meier method. Overall survival was determined by the time 
from BLTx to death or to last follow-up through December 31, 2013.

\section{Results}

\section{Recipient characteristics}

The total cohort included 25 consecutive patients (13 men, 12 women), with a mean age of $41.8 \pm 13.5$ years (range, $18 \sim 67$ years). At the time of LTx, mean recipient body mass index (BMI) was $18.3 \pm 3.1 \mathrm{~kg} / \mathrm{m}^{2}$ (range, 12.9 $24.1 \mathrm{~kg} / \mathrm{m}^{2}$ ); five recipients $(20 \%)$ were hepatitis B virus (HBV) carriers. Before LTx, 7 (28\%) patients required oxygen supplementation at rest, $6(24 \%)$ patients needed noninvasive mechanical ventilator (MV) support, 9 (36\%) patients depended on invasive MV support (IMV), and 3 (12\%) patients were supported by ECMO combined with IMV. The underlying diseases necessitating transplant included bronchiectasis $(\mathrm{n}=7)$, lymphangioleiomyomatosis $(n=5)$, bronchiolitis obliterans $(n=4)$, pulmonary arterial hypertension $(\mathrm{n}=3)$, pneumoconiosis $(\mathrm{n}=3)$, idiopathic pulmonary fibrosis $(\mathrm{n}=2)$, and chronic obstructive pulmonary disease (COPD) $(\mathrm{n}=1)$ (Table 1$)$.

Table 1 Demographic and preoperative characteristics

\begin{tabular}{lll}
\hline Recipient demographic & $\begin{array}{l}\text { No. or } \\
\text { mean } \pm \text { SD }\end{array}$ & $\begin{array}{l}\text { \% or } \\
\text { rang }\end{array}$ \\
\hline Age, year & $41.8 \pm 13.5$ & $18 \sim 67$ \\
BMI, kg/m ${ }^{2}$ & $18.3 \pm 3.1$ & $12.9-24.1$ \\
Sex Female & 12 & $48 \%$ \\
HBV carrier & 5 & $20 \%$ \\
Respiratory status before LTx & & \\
Under oxygen at rest & 7 & $28 \%$ \\
Noninvasive MV & 6 & $24 \%$ \\
Invasive MV & 9 & $36 \%$ \\
ECMO (+invasive MV) & 3 & $12 \%$ \\
Diagnosis & & \\
Bronchiectasis & 7 & $28 \%$ \\
Not associated with CF & 6 & $24 \%$ \\
Associated with CF & 1 & $4 \%$ \\
LAM & 5 & $20 \%$ \\
BO & 4 & $16 \%$ \\
PAH & 3 & $12 \%$ \\
Pneumoconiosis & 3 & $12 \%$ \\
IPF & 2 & $8 \%$ \\
COPD & 1 & $4 \%$ \\
\hline
\end{tabular}

BMI: Body mass index; HBV: Hepatitis B virus. MV: Mechanical Ventilator. ECMO: Extracorporeal membrane oxygenation. CF: Cystic fibrosis.

LAM: Lymphangioleiomyomatosis; BO: Bronchiolitis obliterans. PAH: Pulmonary arterial hypertension; IPF: Idiopathic pulmonary fibrosis. COPD: Chronic obstructive pulmonary disease.

\section{Donor characteristics}

The mean donor age was $27 \pm 11$ years (range, 15 53 years). Seven (28\%) donors were female and $8(32 \%)$ donors had a smoking history. The causes of brain death were head trauma $(n=18,72 \%)$, cerebrovascular accidents $(n=5,20 \%)$, and other conditions $(n=2,8 \%)$. Before harvest, the best ratio of arterial partial pressure of oxygen $\left(\mathrm{PaO}_{2}\right)$ to $100 \%$ fraction of inspired oxygen $\left(\mathrm{FiO}_{2}\right)$ was $513 \pm 77$ (range, $350 \sim 674$ ) and the mean time dependent on the ventilator was $66 \pm 52$ hours (range, $23 \sim 252$ hours) (Table 2). The transplant variables used to match donors and recipients are presented in Table 2 and included negative cross-match results $(100 \%)$, same ethnic origin (100\%), gender (64\%), identical blood group (68\%), compatible blood group (32\%), and cytomegalovirus (CMV) status (96\%).

\section{Operative and postoperative characteristics}

The mean time between placement on the waiting list and transplantation was $308 \pm 261$ days (range 19 1064 days). The ischemic times for the first and second grafts were $222 \pm 62$ minutes (range $125 \sim 337$ minutes) and $361 \pm 67$ minutes (range $253 \sim 463$ minutes). ECMO was

Table 2 Donor characteristics

\begin{tabular}{lll}
\hline Donor demographic & $\begin{array}{l}\text { No. or } \\
\text { mean } \pm \text { SD }\end{array}$ & $\begin{array}{l}\% \text { or } \\
\text { range }\end{array}$ \\
\hline Donor variables & $26.8 \pm 11.4$ & $15 \sim 53$ \\
Age, years & 7 & $28 \%$ \\
Female & 8 & $32 \%$ \\
Cigarette use & & \\
Cause of brain death & 18 & $72 \%$ \\
Head trauma & 5 & $20 \%$ \\
CVA & 2 & $8 \%$ \\
Others & $513 \pm 77$ & $350-674$ \\
Best PaO ${ }_{2}$ /FiO 2 ratio & $66 \pm 52$ & $23-252$ \\
Time on ventilator, hours & & \\
Transplant variables & 25 & $100 \%$ \\
Cross-match negative & 25 & $100 \%$ \\
Same-race matching & 16 & $64 \%$ \\
Same-sex matching & & \\
Blood-group matching & & $68 \%$ \\
Identical & 17 & $32 \%$ \\
Compatible & 8 & \\
CMV matching & & \\
D (+), R (+) & & \\
D (+), R (-) & & \\
\hline
\end{tabular}

CVA: Cerebrovascular accident.

$\mathrm{PaO}_{2} / \mathrm{FiO}_{2}$ : Arterial partial pressure of oxygen/a fraction of inspired oxygen.

CMV: Cytomegalovirus; D (+): Positive CMV result of Donor serum.

$R(+)$ : Positive CMV result of recipient serum.

$\mathrm{R}(-)$ : Negative CMV result of recipient serum. 
used during transplantation for $22(88 \%)$ recipients, and 1 recipient (4\%) required the heart-lung machine for cardiopulmonary bypass. For maximal utilization of available resources, 13 (52\%) donor lungs underwent concomitant resection of unhealthy areas intraoperatively. Seven of 13 donor surgeries were anatomical lobectomies (three for downsizing resection and four for localized pathological present), and the others were volume-reduction surgeries for size mismatching (Table 3).

\section{Survival}

The intensive care stay after BLTx was $45 \pm 24$ days (range 15 98 days), and the total hospital stay was $76 \pm$ 45 days (range $21 \sim 206$ days). Two recipients died (1 primary graft failure, 1 pulmonary infection) within 3 months; the other recipients (92\%) were discharged home without incident and followed up regularly as outpatients. By the end of the study period, four of these discharged recipients had died. The causes of death were pulmonary infection $(\mathrm{n}=2)$, sepsis $(\mathrm{n}=1)$, and bronchiolitis obliterans syndrome $(\mathrm{n}=1)$ (Table 4$)$. The mean survival of all 25 patients was $1272 \pm 784$ days (range $21 \sim 2544$ days). Kaplan-Meier survival for all patients after BLTx at 1-, 2-, 3-, 5- years was $88 \%, 83 \%$, $72 \%$, and $72 \%$, respectively (Figure 1 ).

\section{Discussion}

This retrospective study presents the long-term outcome of 25 consecutive patients receiving BLTx in a low-volume center. This report demonstrated that the satisfactory outcome can be achieved using the urgency-based organ allocation criteria in a donor-scare country.

According to the TORSC report, the average annual organ donation rate after brain death in Taiwan was

Table 3 Operative data

\begin{tabular}{lll}
\hline Demographics & $\begin{array}{l}\text { No. or } \\
\text { mean } \pm \text { SD }\end{array}$ & $\begin{array}{l}\% \text { or } \\
\text { range }\end{array}$ \\
\hline $\begin{array}{l}\text { Time on waiting list, days } \\
\text { Intraoperative }\end{array}$ & $308 \pm 261$ & $19-1064$ \\
$\quad$ Ischemic time, minutes & & \\
First graft & $222 \pm 62$ & $125-337$ \\
Second graft & $361 \pm 67$ & $253-463$ \\
ECMO or CPB support & 23 & $92 \%$ \\
ECMO & 22 & $88 \%$ \\
CPB & 1 & $4 \%$ \\
Concomitant surgical procedures & 13 & $52 \%$ \\
for donor lung & & $28 \%$ \\
lobectomy & 7 & $24 \%$ \\
$\quad$ Other graft size reductions & 6 & \\
\hline
\end{tabular}

ECMO: Extracorporeal membrane oxygenation. CPB: Cardiopulmonary bypass.
Table 4 Postoperative outcome

\begin{tabular}{lll}
\hline Demographics & $\begin{array}{l}\text { No. or } \\
\text { mean } \pm \text { SD }\end{array}$ & $\begin{array}{l}\text { \% or } \\
\text { range }\end{array}$ \\
\hline Postoperative & $45 \pm 24$ & $15-98$ \\
ICU length of stay, days & $76 \pm 45$ & $21-206$ \\
$\quad$ Hospital length of stay, days & 2 & $8 \%$ \\
Cause of death within less than 90 days & 1 & $4 \%$ \\
$\quad$ Primary graft failure & 1 & $4 \%$ \\
Pulmonary infection & 4 & $16 \%$ \\
Cause of death on day 90 or thereafter & 2 & $8 \%$ \\
$\quad$ Pulmonary infection & 1 & $4 \%$ \\
Sepsis & 1 & $4 \%$ \\
BOS & $1272 \pm 784$ & $21-2544$ \\
Survival, days &
\end{tabular}

ICU: Intensive care unit.

BOS: Bronchiolitis obliterans syndrome.

around 6.5 per million of population (PMP) in recent years, which is far below that of Spain (35.3 PMP), Belgium (30.1 PMP), Portugal (28.1 PMP), the U.S.A. (25.6 PMP) and France (25 PMP). The low donation rate in Taiwan creates a severe shortage of donor lungs and limits the annual number of LTx. Ample evidence now exists confirming a relationship between surgical outcome and volume of the procedure, which becomes especially important for complex procedures such as transplantation [3-6]. Weiss et al. reported that the cumulative risk of mortality at 30 days, 1 year, and 5 years after LTx was highly dependent on volume. In general, high-volume centers (those centers achieving an average of 20 LTx per year) had superior short- and long-term outcomes, and low-volume centers (those centers achieving less than 10 LTx per year) have alarmingly high mortality rates. In Taiwan, none of the seven authorized LTx centers have been able to reach 10 LTx per year due to the low organ donation rate. Based on these findings, it is

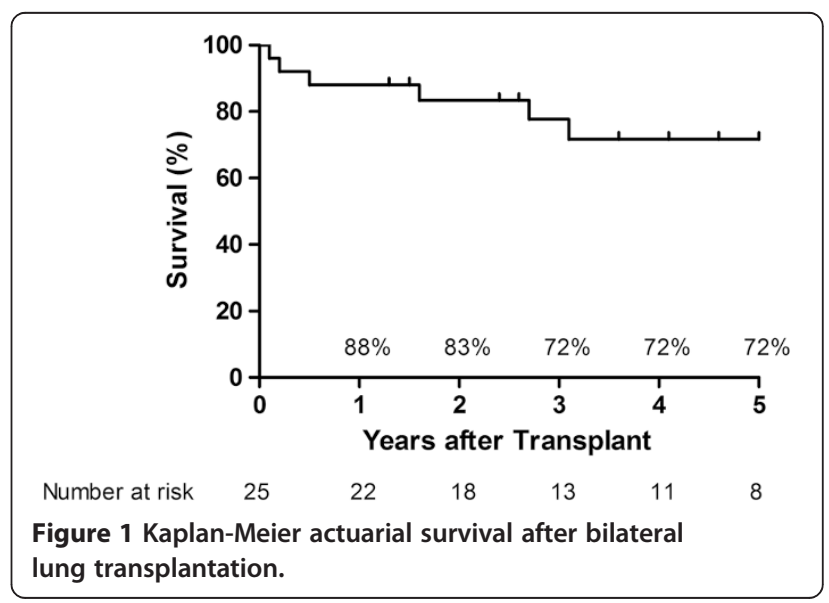


easier to understand why the official report of national LTx outcomes in Taiwan is worse than those reported by the ISHLT. Interestingly, some low-volume centers have been able to produce excellent outcomes, implying that factors influencing mortality after LTx are far more complex than simply volume. Weiss et al. speculate that lowvolume centers may be able to provide similar outcomes as the high-volume centers if they are equipped with specialized staff, integrated patient support systems, and a culture of excellence. These characteristics provide a benchmark for LTx centers to strive for, no matter the size or volume of the center.

The other important issue that significantly impacts transplant outcomes is the organ allocation system. The new allocation rules implemented in France since 2007, which prioritize allocation of donor lungs to candidates with conditions posing an immediate threat to life, are similar to those in Taiwan. The national LTx report from France demonstrated that the survival results for emergency LTx (ELTx) were worse than those for non-urgent LTx [7]. Survival rates in the ELTx group were $64.5 \%$ and $55 \%$ at 1 and 2 years, respectively, which were significantly lower than the regular, nonurgent LTx group (77\% and 71\%, respectively). As with France's experience, Spain and the United States also have similarly poor outcomes for emergent or urgent LTx [8,9]. According to the United Network for Organ Sharing (UNOS) data, patients on MV or ECMO before LTx had decreased survival after LTx [10]. The 1-year survival associated with ventilator and ECMO support groups were 67.7\% and $57.6 \%$, respectively, which were both inferior to those in the high lung allocation score group. Based on these findings, it is reasonable to conclude that this kind of urgency-based allocation policy may contribute to futile and unsuccessful transplantation, especially for lowvolume, limited experience LTx centers in donor-scare countries, such as those in Taiwan.

Our report is consistent with the conclusion that lung allocation policy has great influence on the distribution of underlying disease indications for LTx. Although COPD was one of the major diagnoses for LTx in the UNOS and ISHLT reports, only one patient with COPD (4\%) received LTx in our study population $[1,11]$. This unique phenomenon may result from the urgency-based lung allocation system in Taiwan. These allocation rules could potentially make access to LTx more difficult for patients not fulfilling the emergency criteria when donor lungs are scarce, gradually leading to an increase in waiting-list mortality for non-urgent patients, such as those with COPD.

In this study, eighteen (72\%) patients were already dependent on MV or ECMO support prior to LTx. In order to provide adequate hemodynamic support during LTx, ECMO was used preferentially as an alternative to cardiopulmonary bypass (CPB). We prefer the ECMO circuit to assist LTx instead of CPB for several reasons. First, modern ECMO technology, including replacement of silicone oxygenators, the introduction of heparinbonded circuits, and new centrifugal pumps, gives ECMO the capacity to support gas exchange without the need for high-dose heparin administration or anticoagulation therapy. Second, our institution is one of the highest-volume ECMO centers in the world. In our institution since 1994, more than 1,950 patients have been treated with ECMO for sundry causes of cardiopulmonary collapse. Therefore, the refined technical aspects of ECMO combined with the experience using ECMO in our hospital significantly decreases the incidence of major ECMO-attributed complications, including bleeding and peripheral access-related limb ischemia, in our transplant population. Finally, ECMO can provide a bridge to transplantation in patients unresponsive to maximal pulmonary-respiratory support [12-15]. In this report, of 23 patients (92\%) receiving BLTx under ECMO support, only one needed to switch to traditional cardiopulmonary bypass (due to severe hemodynamic instability). Furthermore, ECMO allowed $3(12 \%)$ patients cardiopulmonary failure to be stabilized before LTx and thus be successfully bridged (up to 86 days) to BLTx in a high-urgency setting; each of these patients was weaned off ECMO smoothly and discharged without any complications.

The 1-, 3-, and 5-year survival rates after BLTx in this study are similar to those of the Japanese registry report (86\%, $79 \%$, and $73 \%$ ), and are slightly superior to those from UNOS $(84 \%, 66 \%, 51 \%)$ and ISHLT $(79 \%, 64 \%$, $53 \%)[11,16,17]$. Given the small sample size in our study, we can only speculate on the reasons for our improved outcomes. Most likely, a combination of specialized staff, operative technique, and optimal recipientdonor matching (100\% cross match and race matching, and only $4 \%$ CMV mismatching) is responsible for these outcomes; however, further investigation of these trends is warranted to confirm this speculation.

This study is limited by its single-institution, small sample size, and retrospective nature. Moreover, there was no control group to reduce the influence of selection bias. However, a control group may present ethical challenges because LTx is a promising, feasible and lifesaving procedure for patients with end-stage pulmonary disease.

\section{Conclusions}

Owing to refined surgical technique, adequate perioperative support, and improved postoperative care, we believe LTx can be performed with acceptable post-transplant mortality and satisfactory long-term outcomes in a lowvolume center such as ours using the urgency-based organ allocation criteria. 


\section{Abbreviations}

BLTX: Bilateral lung transplantation; LTX: Lung transplantation; TORSC: Taiwan Organ Registry and Sharing Center; ISHLT: International Society for Heart and Lung Transplantation; ECMO: Extracorporeal membrane oxygenation; ICU: Intensive care unit; BMI: Body mass index; HBV: Hepatitis B virus; MV: Mechanical ventilator; COPD: Chronic obstructive pulmonary disease: CMV: Cytomegalovirus; PMP: Per million of population; UNOS: United Network for Organ Sharing; CPB: Cardiopulmonary bypass.

\section{Competing interests}

No author has financial or other interest in the product or distributor of the product involved in the present study.

\section{Authors' contributions}

SMY, HHH, SCH, SWK, PMH, SCP, and JML were all involved in the transplant surgery, including the donor procurement and recipient transplantation. $\mathrm{SCH}$, SWK, and SMY set up and maintained the ECMO life support system. HHH, SMY, SCH, and HSL has been involved in drafting the manuscript and also made substantial contributions to conception and design of the study, and acquisition of data. HHH, SCH, SWK, SMY, SCP, and JML were also involved in the postoperative patients' care. SMY, SWK, PMH, HSL, and JML substantial contributions to conception and design as well as interpretation of data. $\mathrm{HHH}$ was the director responsible for general organization and instruction. All authors read and approved the final manuscript.

\section{Acknowledgements}

We would like to thank Yu-Mei Lai for providing the assist in the collection of patients' information. There was no source of support for this study.

\section{Author details}

'Department of Surgery, National Taiwan University Hospital and National Taiwan University College of Medicine, No. 7, Chung-Shan South Road, Taipei, Taiwan. ${ }^{2}$ Department of Internal Medicine, National Taiwan University Hospital and National Taiwan University College of Medicine, No. 7, Chung-Shan South Road, Taipei, Taiwan.

\section{Received: 16 March 2014 Accepted: 13 February 2015}

\section{Published online: 18 March 2015}

\section{References}

1. Christie JD, Edwards LB, Kucheryavaya AY, Benden C, Dipchand Al, Dobbels $F$, et al. The registry of the international society for heart and lung transplantation: 29th adult lung and heart-lung transplant report-2012. $J$ Heart Lung Transplant: the official Publ Int Soc Heart Transplant. 2012;31(10):1073-86.

2. Hsu HH, Chen JS, Ko WJ, Huang SC, Kuo SW, Huang PM, et al. Short-term outcomes of cadaveric lung transplantation in ventilator-dependent patients. Crit Care. 2009;13(4):R129.

3. Weiss ES, Allen JG, Meguid RA, Patel ND, Merlo CA, Orens JB, et al. The impact of center volume on survival in lung transplantation: an analysis of more than 10,000 cases. Ann Thorac Surg. 2009;88(4):1062-70.

4. Luft HS, Bunker JP, Enthoven AC. Should operations be regionalized? The empirical relation between surgical volume and mortality. N Engl J Med. 1979;301(25):1364-9.

5. Hosenpud JD, Breen TJ, Edwards EB, Daily OP, Hunsicker LG. The effect of transplant center volume on cardiac transplant outcome. A report of the united network for organ sharing scientific registry. JAMA. 1994;271 (23):1844-9.

6. Weiss ES, Meguid RA, Patel ND, Russell SD, Shah AS, Baumgartner WA, et al. Increased mortality at low-volume orthotopic heart transplantation centers: should current standards change? Ann Thorac Surg. 2008;86(4):1250-9. discussion 1259-1260.

7. Boussaud V, Mal H, Trinquart L, Thabut G, Danner-Boucher I, Dromer C, et al. One-year experience with high-emergency lung transplantation in France. Transplant. 2012;93(10):1058-63.

8. Roman A, Calvo V, Ussetti P, Borro JM, Lama R, Zurbano F, et al. Urgent lung transplantation in Spain. Transplant Proc. 2005:37(9):3987-90.

9. Algar FJ, Moreno P, Cano JR, Espinosa D, Alvarez A, Cerezo F, et al. Urgencycode lung transplantation for cystic fibrosis: experience and results. Transplant Proc. 2008;40(9):3067-9.
10. Mason DP, Thuita L, Nowicki ER, Murthy SC, Pettersson GB, Blackstone EH. Should lung transplantation be performed for patients on mechanical respiratory support? The US experience. J Thorac Cardiovasc Surg. 2010;139(3):765-73. e761.

11. Yusen RD, Christie JD, Edwards LB, Kucheryavaya AY, Benden C, Dipchand $\mathrm{Al}$, et al. The registry of the international society for heart and lung transplantation: thirtieth adult lung and heart-lung transplant report-2013; focus theme: age. J Heart Lung Transplant: the official Publ Int Soc Heart Transplant. 2013;32(10):965-78.

12. Hammainen P, Schersten H, Lemstrom K, Riise GC, Kukkonen S, Sward K, et al. Usefulness of extracorporeal membrane oxygenation as a bridge to lung transplantation: a descriptive study. J Heart Lung Transplant: the official Publ Int Soc Heart Transplant. 2011:30(1):103-7.

13. Bittner HB, Lehmann S, Rastan A, Garbade J, Binner C, Mohr FW, et al. Outcome of extracorporeal membrane oxygenation as a bridge to lung transplantation and graft recovery. Ann Thorac Surg. 2012;94(3):942-9. author reply 949-950.

14. Javidfar J, Brodie D, Iribarne A, Jurado J, Lavelle M, Brenner K, et al. Extracorporeal membrane oxygenation as a bridge to lung transplantation and recovery. J Thorac Cardiovasc Surg. 2012;144(3):716-21.

15. Hsu HH, Ko WJ, Chen JS, Lin CH, Kuo SW, Huang SC, et al. Extracorporeal membrane oxygenation in pulmonary crisis and primary graft dysfunction. $J$ Heart Lung Transplant: the official Publ Int Soc Heart Transplant. 2008;27(2):233-7.

16. Oto T, Okada Y, Bando T, Minami M, Shiraishi T, Nagayasu T, et al. Registry of the Japanese society of lung and heart-lung transplantation: the official Japanese lung transplantation report 2012. Gen Thorac Cardiovasc Surg. 2013;61(4):208-11.

17. Lodhi SA, Lamb KE, Meier-Kriesche HU. Solid organ allograft survival improvement in the United States: the long-term does not mirror the dramatic short-term success. Am J Transpl: official J Am Soc Transplant and the Am Soc Transplant Surgeons. 2011;11(6):1226-35.

\section{Submit your next manuscript to BioMed Central and take full advantage of:}

- Convenient online submission

- Thorough peer review

- No space constraints or color figure charges

- Immediate publication on acceptance

- Inclusion in PubMed, CAS, Scopus and Google Scholar

- Research which is freely available for redistribution 